\title{
OPEN High efficacy of microbial larvicides for malaria vectors control in the city of Yaounde Cameroon following a cluster randomized trial
}

\author{
Christophe Antonio-Nkondjio ${ }^{1,5}$, P. Doumbe-Belisse ${ }^{1,3}$, L. Djamouko-Djonkam ${ }^{1,4}$, \\ C. S. Ngadjeu ${ }^{1,3}$, A. Talipouo $0^{1,3}$, E. Kopya ${ }^{1,3}$, R. Bamou ${ }^{1,4}$, M. P. Audrey Mayi ${ }^{4}$, \\ N. Sonhafouo-Chiana ${ }^{1,2}$, D. L. Nkahe ${ }^{3}$, R. Tabue ${ }^{6}$, D. Achu Fosah ${ }^{6}$, Jude D. Bigoga ${ }^{7,8}$, \\ P. Awono-Ambene ${ }^{1} \&$ Charles S. Wondji5,9
}

The rapid expansion of insecticide resistance and outdoor malaria transmission are affecting the efficacy of current malaria control measures. In urban settings, where malaria transmission is focal and breeding habitats are few, fixed and findable, the addition of anti-larval control measures could be efficient for malaria vector control. But field evidences for this approach remains scarce. Here we provide findings of a randomized-control larviciding trial conducted in the city of Yaounde that support the efficacy of this approach. A two arms random control trial design including 26 clusters of 2 to $4 \mathrm{~km}^{2}$ each (13 clusters in the intervention area and 13 in the non-intervention area) was used to assess larviciding efficacy. The microbial larvicide VectoMax combining Bacillus thuringiensis var israelensis (Bti) and Bacillus sphaericus in a single granule was applied every 2 weeks in all standing water collection points. The anopheline density collected using CDC light traps was used as the primary outcome, secondary outcomes included the entomological inoculation rate, breeding habitats with anopheline larvae, and larval density. Baseline entomological data collection was conducted for 17 months from March 2017 to July 2018 and the intervention lasted 26 months from September 2018 to November 2020. The intervention was associated with a reduction of $68 \%$ of adult anopheline biting density and of $79 \%$ of the entomological inoculation rate (OR $0.21 ; 95 \% \mathrm{Cl} 0.14-0.30, P<0.0001)$. A reduction of $68.27 \%$ was recorded for indoor biting anophelines and $57.74 \%$ for outdoor biting anophelines. No impact on the composition of anopheline species was recorded. A reduction of over $35 \%$ of adult Culex biting densities was recorded. The study indicated high efficacy of larviciding for reducing malaria transmission intensity in the city of Yaoundé. Larviciding could be part of an integrated control approach for controlling malaria vectors and other mosquito species in the urban environment.

Africa's population almost doubled during the last two decades, from about 665 million in 2000 to 1.1 billion in $2019^{1}$. This rapid demographic growth has resulted in a massive migration of the population from rural to urban areas. The rapid demographic changes in major sub-Saharan Africa cities which are also associated to large-scale unplanned urbanization including poor housing, poor drainage, inadequate waste management, multiplication of slums and environmental changes have significantly influenced the epidemiology of vector-borne diseases such as malaria and arboviruses and population health ${ }^{2-5}$. Malaria remains an important public health problem

\footnotetext{
${ }^{1}$ Laboratoire de Recherche Sur Le Paludisme, Organisation de Coordination Pour La Lutte Contre Les Endémies en Afrique Centrale (OCEAC), P.O. Box 288, Yaoundé, Cameroun. ${ }^{2}$ Faculty of Sciences, University of Buea, P.O. Box 63, Buea, Cameroon. ${ }^{3}$ Faculty of Sciences, University of Yaoundé I, P.O. Box 337, Yaoundé, Cameroon. ${ }^{4}$ Vector Borne Diseases Laboratory of the Biology and Applied Ecology Research Unit (VBID-URBEA), Department of Animal Biology, Faculty of Science of the University of Dschang, Dschang, Cameroon. ${ }^{5}$ Department of Vector Biology, Liverpool School of Tropical Medicine Pembroke Place, Liverpool L3 50A, UK. 'Ministry of Public Health, National Malaria Control Programme, Yaoundé, Cameroon. ${ }^{7}$ Laboratory for Vector Biology and Control, National Reference Unit for Vector Control, The Biotechnology Center, Nkolbisson-University of Yaounde I, P.O. Box 3851, Messa, Yaoundé, Cameroon. ${ }^{8}$ Department of Biochemistry, Faculty of Science, University of Yaounde I, Yaoundé, Cameroon. ${ }^{9}$ Centre for Research in Infectious Diseases, Yaoundé, Cameroon. ${ }^{\square}$ email: antonio_nk@yahoo.fr
} 
across the world affecting both rural and urban areas ${ }^{6-9}$. According to the latest world malaria report, 229 million malaria cases were reported in $2019^{10}$. Long-lasting insecticidal nets (LLINs) and indoor residual spraying (IRS) are considered as the cornerstone for malaria prevention ${ }^{11}$.

The large-scale deployment of these tools permitted to avoid about 1.5 billion malaria cases and 7.6 million malaria deaths between 2000 and $2019^{12}$. Roughly 1.9 billion LLINs have been distributed in sub-Saharan Africa between 2004 and $2019^{10}$. It is estimated that about $68 \%$ of households in sub-Saharan Africa had at least one LLIN in 2019 this suggesting a terrific increase compared to $5 \%$ in $2000^{10}$. However, control efforts are still affected by the rapid expansion of insecticide resistance. Almost all sub-Saharan countries have reported resistance to all four of the most commonly used insecticide classes ${ }^{13,14}$. Resistance to pyrethroids the compound used for impregnating bed nets is widespread ${ }^{13,15,16}$. Based on insecticide resistance monitoring data, many countries are now adopting new strategies to manage insecticide resistance and improve malaria control. These include switching to new control tools such as the deployment of pyrethroid-piperonyl butoxide (PBO) nets ${ }^{17}$ or the combination of different control tools or interventions ${ }^{18,19}$.

Larval source management (LSM) has proven in the past to be highly effective for lowering malaria transmission and even eliminating malaria vectors and disease transmission ${ }^{20-22}$. Historical literature reveals that the use of anti-larval mosquito control measures contributed to all successful eradication efforts ${ }^{23-25}$. Several studies reporting significant impact of larval control on malaria transmission or malaria morbidity have been registered across the continent ${ }^{20,26,27}$. However, despite historical facts and new evidences on larviciding efficacy this intervention is still not largely implemented for malaria control in sub-Saharan Africa due to the limited number of unbiased studies on its efficacy or effectiveness ${ }^{27,28}$. Systematic reviews produced in the recent years ${ }^{27,29,30}$, indicated low certainty evidences due to poor study design for many studies ${ }^{27,30}$. The World Health Organization (WHO) issued an interim position on larviciding recommending its use in moderate to low transmission settings as a supplement to core interventions (LLINs and IRS) in areas where aquatic habitats are few fixed and findable ${ }^{11}$. The intervention could be particularly indicated in urban settings or in highland areas where aquatic habitats are less important and malaria transmission moderate ${ }^{31-33}$. According to the WHO guidelines ${ }^{34}$, LSM could be integrated into malaria control or general mosquito abatement programmes once transmission has been reduced to low or moderate levels after the use of LLINs or IRS, or once these interventions have reached their maximum practical impact.

In Cameroon malaria remains an important public health problem. Between 2015 and 2018, the incidence of malaria cases increased across the country highlighting the need to intensify malaria control efforts ${ }^{35,36}$. Treated nets are the main measure implemented by the government to prevent malaria attacks. It is estimated that about $80 \%$ of households own a bed net and that close to $60 \%$ use treated nets regularly ${ }^{36}$. Apart from LLINs which were introduced in the country in the 1990s, there have been two pilot larval control trials initiated in the country to control Culex quinquefasciatus populations. The first one conducted in the 1990s in the city of Maroua which consisted of two treatments per year of all breeding habitats with Bacillus sphaericus as larvicide had a limited impact on the biting densities of C. quinquefasciatus mosquito populations ${ }^{36}$. The second pilot study conducted in Yaounde registered a 64\% reduction of C. quinquefasciatus biting densities. However, because the authors did not included any control cluster the interpretation of their findings was limited ${ }^{37}$.

The city of Yaounde has a landscape with an alternation of both highland and lowland areas with over $90 \%$ of aquatic habitats located in lowland settings and could be an excellent environment to practice larviciding ${ }^{38,39}$. The population is approximately 3 million inhabitants and is characterised by a low malaria transmission pattern ${ }^{40,41}$. There have been so far not enough attempts to control malaria vectors using interventions suited to the landscape and ecological situation of the environment. We hypothesized that the implementation of larviciding in the city of Yaounde could result in over $40 \%$ reduction of mosquito biting densities and subsequently the entomological inoculation rate compare to sites where this intervention is not implemented. Generating evidences on the efficacy of larviciding in different epidemiological context could improve malaria control across Africa. In the course of the present study, a cluster randomised trial including 26 clusters of 2 to $4 \mathrm{~km}^{2}$ each divided into 2 groups 13 in the intervention area and 13 in the non-intervention area was conducted to assess the impact of larviciding on malaria transmission in the city of Yaoundé.

\section{Results}

Household characteristics. Baseline community and entomological surveys were conducted from February 2017 to July 2018. Some data deriving from these studies have been published previously ${ }^{42-49}$. Household characteristics were almost similar across the two study groups. Modern houses built up with cement $(50 \%$ and $62.77 \%$ ) and traditional houses constructed with mud, plank, and mix material (50\% and $37.23 \%$ ) were recorded. Most households (> 84\%) owned at least a LLIN, $47 \%$ and $48 \%$ of households in the control and intervention area respectively had one LLIN for two people (Table 1). The majority of households had an average of 6 to 10 persons per household. Close to $20 \%$ of houses had screens on windows. The number of houses with ceilings was also similar between the two groups.

Monthly distribution of anopheline larvae. Anopheline larval abundance was seasonal with high density during the short and long rainy seasons. The annual rainfall estimates was $761.4 \mathrm{~mm}$ in $2017,845.4 \mathrm{~mm}$ in $2018,3011.3 \mathrm{~mm}$ in 2019 and $2726.2 \mathrm{~mm}$ in $2020^{50}$. This pattern influenced breeding habitats availability and distribution in the city (Table 2).

The proportion of habitats found with early or late instar anopheles larvae at baseline was $13.32 \%(1150 / 8633)$ in intervention area and $18.66 \%(1551 / 8313)$ in non-intervention area. During the intervention period, only $0.80 \%$ of sites $(1102 / 137,120)$ were found with anopheline larvae after larviciding treatments whereas, in nonintervention areas, $7.52 \%$ of sites $(1934 / 25,729)$ were found with anopheline larvae. Taking into account the 


\begin{tabular}{|c|c|c|c|c|c|}
\hline \multirow[b]{2}{*}{ Characteristics } & \multirow[b]{2}{*}{ Factors } & \multicolumn{2}{|c|}{$\begin{array}{l}\text { Non-intervention } \\
\text { areas }\end{array}$} & \multicolumn{2}{|c|}{ Intervention areas } \\
\hline & & N houses & $\%$ & N houses & $\%$ \\
\hline \multirow{2}{*}{ Type of house } & Modern & 94 & 50.00 & 118 & 62.77 \\
\hline & Traditional & 94 & 50.00 & 70 & 37.23 \\
\hline \multirow{3}{*}{ Occupants } & {$[1-5]$} & 72 & 39.13 & 78 & 43.33 \\
\hline & {$[6-10]$} & 89 & 48.37 & 88 & 48.89 \\
\hline & $\geq 11$ & 23 & 12.50 & 14 & 7.78 \\
\hline \multirow{2}{*}{ Holes on walls } & No & 116 & 63.74 & 134 & 72.04 \\
\hline & Yes & 66 & 36.26 & 52 & 27.96 \\
\hline \multirow{2}{*}{ Eaves } & No & 65 & 36.52 & 78 & 43.58 \\
\hline & Yes & 113 & 63.48 & 101 & 56.42 \\
\hline \multirow{2}{*}{ Ceiling } & No & 124 & 67.03 & 102 & 55.74 \\
\hline & Yes & 61 & 32.97 & 81 & 44.26 \\
\hline \multirow{2}{*}{ Screened windows } & No & 158 & 85.87 & 144 & 80.00 \\
\hline & Yes & 26 & 14.13 & 36 & 20.00 \\
\hline \multirow{2}{*}{$\begin{array}{l}\text { At least one LLIN } \\
\text { Per household }\end{array}$} & No & 28 & 15.05 & 15 & 8.47 \\
\hline & Yes & 158 & 84.95 & 162 & 91.53 \\
\hline \multirow{2}{*}{ Use of LLINs } & No & 24 & 13.04 & 15 & 8.47 \\
\hline & Yes & 160 & 86.96 & 162 & 91.53 \\
\hline \multirow{2}{*}{ owning one LLIN for 2 people } & No & 99 & 52.38 & 98 & 51.65 \\
\hline & Yes & 90 & 47.62 & 91 & 48.35 \\
\hline \multirow{2}{*}{ Vegetation close to the house } & No & 41 & 21.69 & 37 & 19.58 \\
\hline & Yes & 148 & 78.31 & 152 & 80.42 \\
\hline \multirow{2}{*}{ Aquatic habitats close to the house } & No & 32 & 16.93 & 35 & 18.52 \\
\hline & Yes & 157 & 83.07 & 154 & 81.48 \\
\hline
\end{tabular}

Table 1. House characteristics in the non-intervention and intervention areas. $\mathrm{N}$ houses $=$ Number of houses selected for interview and house characterisation; \% percentage of houses, LLINs = Long Lasting Insecticidal Nets; Traditional house: houses with mud or plank walls (poorly constructed); Modern house: houses constructed with bricks or cement walls.

\begin{tabular}{|c|c|c|c|c|c|}
\hline & \multicolumn{2}{|l|}{ Baseline } & \multicolumn{2}{|l|}{ Intervention } & \multirow[b]{2}{*}{ Percent reduction +} \\
\hline & Non-intervention area & Intervention area & Non-intervention area & Intervention area & \\
\hline \multicolumn{6}{|l|}{ Total of aquatic habitats } \\
\hline Checked & 8313 & 8633 & 25,729 & 137,120 & \\
\hline $\begin{array}{l}\text { Total number of water bodies with anopheline larvae (\%) } \\
(95 \% \mathrm{CI})\end{array}$ & $\begin{array}{l}1551(18.66 \%) \\
(17.74-19.61)\end{array}$ & $\begin{array}{l}1150(13.32 \%) \\
(12.56-14.11)\end{array}$ & $\begin{array}{l}1934(7.52 \%) \\
(7.18-7.85)\end{array}$ & $\begin{array}{l}1102(0.80 \%) \\
(0.76-0.85)\end{array}$ & $85.46^{*}$ \\
\hline Total number with late instar anopheline larvae (\%) (95\% CI) & $\begin{array}{l}1096(70.66 \%) \\
(66.54-74.97)\end{array}$ & $\begin{array}{l}772(67.13 \%) \\
(62.48-72.04)\end{array}$ & $\begin{array}{l}1155(59.72 \%) \\
(56.33-63.27) \\
\end{array}$ & $\begin{array}{l}168(15.24 \%) \\
(13.03-17.73)\end{array}$ & $73.13^{*}$ \\
\hline $\begin{array}{l}\text { Total number of water bodies with culicine larvae (\%) (95\% } \\
\text { CI) }\end{array}$ & $\begin{array}{l}1528(18.38 \%) \\
(17.47-19.33)\end{array}$ & $\begin{array}{l}1773(20.54 \%) \\
(19.59-21.52)\end{array}$ & $\begin{array}{l}2523(9.80 \%) \\
(9.42-10.19)\end{array}$ & $\begin{array}{l}5538(4.03 \%) \\
(3.93-4.14)\end{array}$ & $69.24^{*}$ \\
\hline
\end{tabular}

Table 2. Distribution of anopheline and culicine larvae in breeding habitats at baseline and during the larviciding intervention. + Percent reduction $=100-($ Non LCI at baseline/LCI at baseline $\times$ LCI during intervention/non-LCI during intervention) $\times 100$. (Non-larviciding intervention area (Non LCI), Larvicidng Intervention area $(\mathrm{LCI})):{ }^{\star} P \leq 0.001$.

clustering by treatment group and by period, it appeared that larviciding treatment significantly reduced the chances of water bodies being colonised by anopheline larvae $(\mathrm{OR}=0.1595 \% \mathrm{CI}=0.07-0.32 ; P<0.0001)$. The number of breeding habitats with late instar anopheline larvae was also reduced by over $73 \%$. When was considered the effect of larviciding treatments on culicine larvae, a significant reduction of breeding habitats with culicine larvae could also be noticed $(\mathrm{OR}=0.3795 \% \mathrm{CI}=0.32-0.42 ; P<0.0001)$. High fluctuation in the monthly distribution of breeding habitats with anopheline larvae closely associated with the rainfall pattern was recorded (Fig. 1).

Changes in the presence of Anopheles larvae in aquatic habitats. In addition to unadjusted data analysis, a mixed linear modelling approach was used to better assess the impact of larviciding treatments. A total of 1131 measurements in both the intervention and non-intervention areas were taken into considera- 


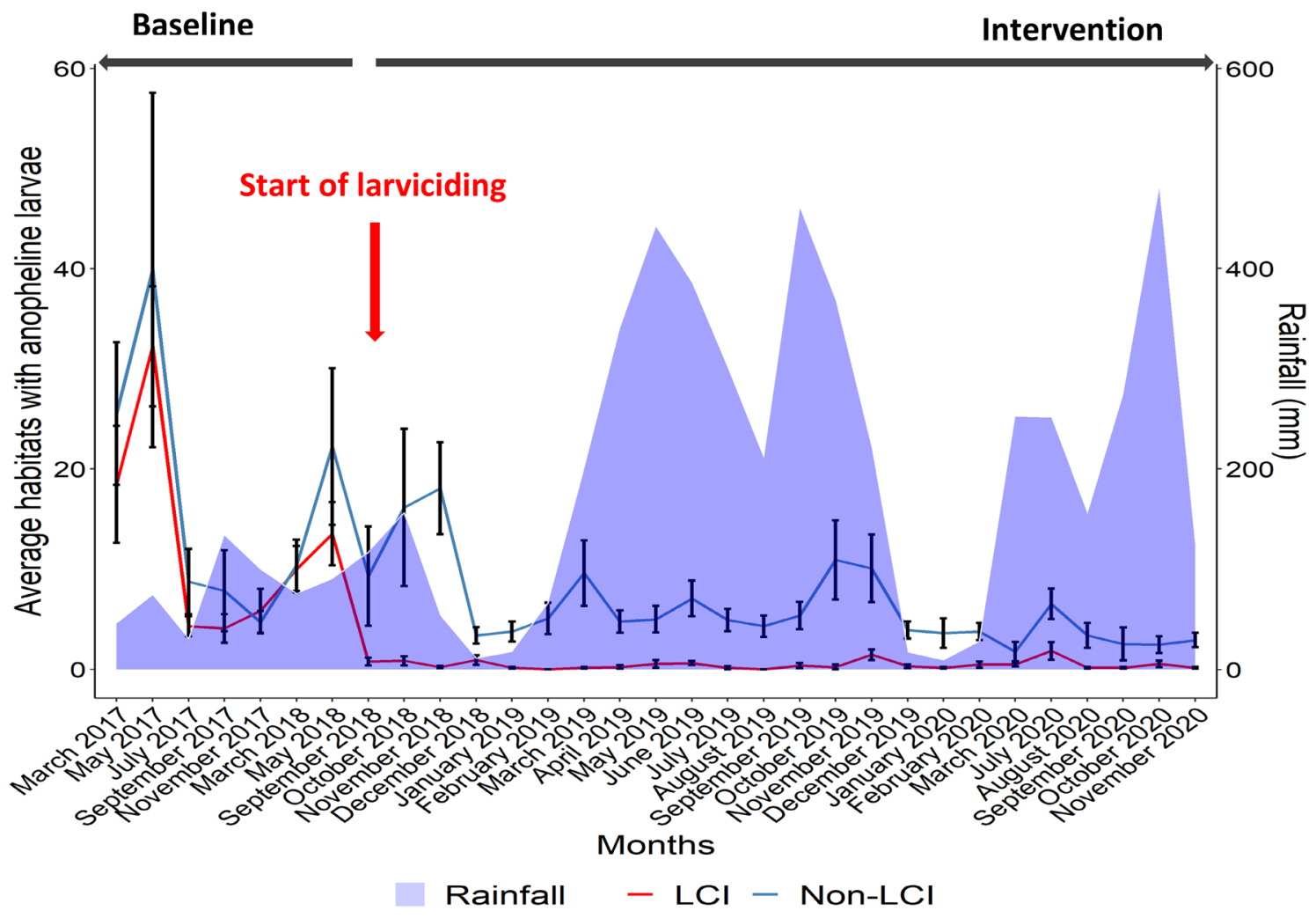

Figure 1. Distribution of aquatic habitats with anopheline larvae before and during the larviciding intervention ((Non-larviciding intervention area (Non LCI), Larvicidng Intervention area (LCI)).

\begin{tabular}{|l|l|l|l|l|}
\hline \multirow{2}{*}{ Parameters } & Baseline & Intervention \\
\cline { 2 - 5 } OR (95\% CI) & $P$ value & OR (95\% CI) & P value \\
\hline Study group & 1 & & & 1 \\
\hline Non-intervention & $1.17(0.69,1.97)$ & 0.56 & $0.02(0.01,0.03)$ & $<0.0001$ \\
\hline Intervention & \multicolumn{5}{|l|}{} \\
\hline Season & 1 & & & 1 \\
\hline Dry & Excluded & & $1.65(1.44,1.90)$ & $<0.0001$ \\
\hline Rainy & 1 & & & 1 \\
\hline Public works & Excluded & & $0.90(0.58,1.40)$ & 0.63 \\
\hline No & 1 & & & 1 \\
\hline Yes & $0.37(0.20,0.67)$ & 0.001 & $0.74(0.61,0.89)$ & 0.001 \\
\hline Flooding & 1 & & & 1 \\
\hline No & $0.71(0.40,1.25)$ & 0.24 & $0.47(0.28,0.79)$ & 0.004 \\
\hline Yes &
\end{tabular}

Table 3. Mixed effects logistic regression models of the impact of larviciding on the distribution of Anopheline larvae, and influence of other parameters during baseline and intervention periods. Public works; refer to construction of roads or buildings, Agricultural activities: refer to the exploitation of land surface for the practice of agriculture; Flooding: refer to inundated areas. OR: odd ratio; 95\% CI: 95\% confidence interval.

tion for the modelling analysis. Results confirmed a significant reduction $(P<0.001)$ of breeding habitats with anopheline larvae in the intervention area compared to the non-intervention area, though a significant decline in the proportion of breeding habitats with Anopheles larvae for both non-intervention and intervention areas was generally observed with time (Table 3). Different factors including season, flooding, agricultural activities were found associated with a significant impact on the OR of the model $(P<0.005)$. 


\begin{tabular}{|c|c|c|c|c|c|}
\hline & \multicolumn{2}{|c|}{ Pre-intervention } & \multicolumn{2}{|l|}{ Intervention } & \multirow[b]{2}{*}{ Total (\%) } \\
\hline & Non LCI N(\%) & LCI N(\%) & Non LCI N(\%) & LCI N(\%) & \\
\hline An. funestus s.l & $152(7.10)$ & $462(18.65)$ & $72(4.75)$ & $131(24.72)$ & $817(12.26)$ \\
\hline An. gambiae s.l & $1976(92.29)$ & $1998(80.66)$ & $1422(93.80)$ & $392(73.96)$ & $5788(86.8)$ \\
\hline An. ziemanni & $13(0.61)$ & $17(0.69)$ & & $7(1.32)$ & $59(0.89)$ \\
\hline Total & $2141(34.98)$ & 2477 (32.35) & $1516(24.21)$ & $530(8.46)$ & 6664 \\
\hline
\end{tabular}

Table 4. Composition of anopheline mosquito fauna in Yaounde. Non-larviciding intervention area (Non LCI), Larviciding Intervention area (LCI).

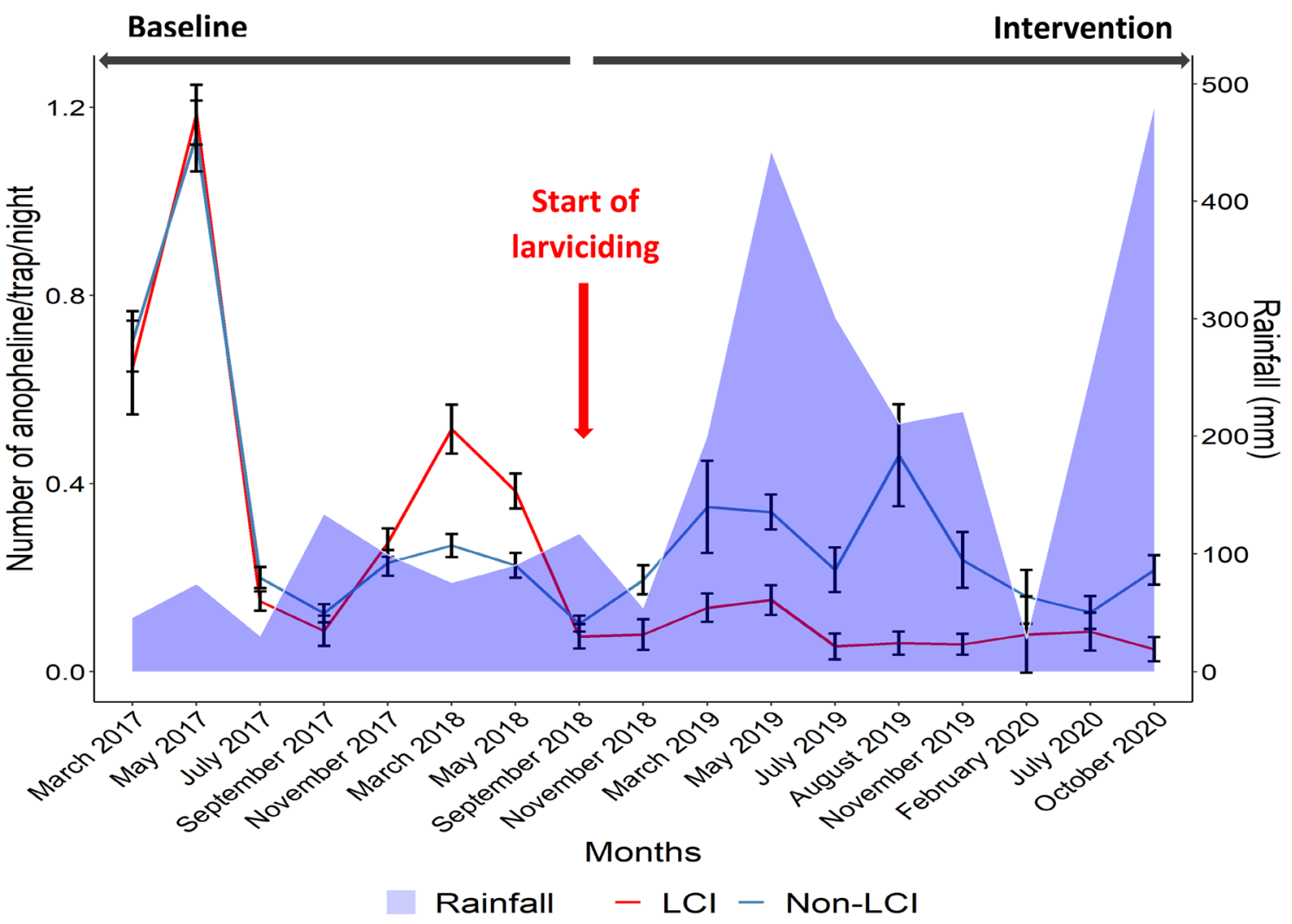

Figure 2. Fluctuation of anopheline biting density before and during larviciding intervention (Non-larviciding intervention area (Non LCI), Larvicidng Intervention area (LCI)).

The influence of physicochemical factors on anopheline larvae presence in aquatic habitats before and during the intervention could be found as Supplementary Table S1. Analysis conducted indicated low influence of these factors.

Adult mosquito abundance. A total of 6664 anophelines were collected in the course of the study. Species collected included An. gambiae s.l., An. funestus and An. ziemanni (Table 4). A subsample of 2762 An. gambiae s.l., was processed by PCR and both An. coluzzii (88.42\%) and An. gambiae (11.58\%) were recorded. Within the An. funestus group, out of 299 mosquitoes processed, 280 (93.65\%) were An. funestus s.s., and 19 (6.35\%) were $A n$. leesoni. In almost all districts An. coluzzii was the predominant species; followed by An. gambiae. No significant variation in the composition of An. gambiae and An. coluzzii before and during the intervention was recorded in both the intervention and non-intervention areas $(P>0.20)$ (The distribution of species before and during larviciding could be found in the Supplementary Figure S1). An. funestus was recorded in few sites and was particularly abundant in the site of Mendong located close to the periphery with large swamps.

Adult vector density was higher at baseline than for subsequent years throughout intervention in both the intervention and non-intervention areas (Fig. 2). After launching the intervention, a steady decrease in vector density was recorded in the intervention area. The average density of anopheline collected in the non-intervention clusters varied from 0.42 anopheline/trap/night at baseline to 0.23 anopheline/trap/night during the intervention. In the intervention clusters the average density of anopheline collected by CDC light traps varied from 0.47 anopheline/trap/night at baseline to 0.082 anopheline/trap/night during intervention. Larviciding was associated 


\begin{tabular}{|c|c|c|c|c|c|}
\hline \multirow[b]{2}{*}{ Parameters } & \multicolumn{2}{|l|}{ Baseline } & \multicolumn{2}{|l|}{ Intervention } & \multirow[b]{2}{*}{ Percent reduction* } \\
\hline & $\begin{array}{l}\text { Non-intervention area }(95 \% \\
\text { CI) }\end{array}$ & Intervention area $(95 \% \mathrm{CI})$ & $\begin{array}{l}\text { Non-intervention area }(95 \% \\
\text { CI) }\end{array}$ & Intervention area $(95 \% \mathrm{CI})$ & \\
\hline $\begin{array}{l}\text { Mean number of Anopheles } \\
\text { per trap per night } 95 \% \text { CI }\end{array}$ & $0.42(0.40-0.44)$ & $0.47(0.45-0.49)$ & $0.23(0.22-0.25)$ & $0.082(0.075-0.09)$ & 68.14 \\
\hline Indoor & $0.62(0.59-0.65)$ & $0.67(0.64-0.70)$ & $0.35(0.33-0.37)$ & $0.12(0.11-0.13)$ & 68.27 \\
\hline Outdoor & $0.12(0.11-0.134)$ & $0.12(0.10-0.13)$ & $0.071(0.06-0.08)$ & $0.03(0.02-0.03)$ & 57.74 \\
\hline $\begin{array}{l}\text { Mean number of Culicine per } \\
\text { trap per night } 95 \% \text { CI }\end{array}$ & $15.67(15.56-15.77)$ & $17.20(17.09-17.31)$ & $10.89(10.82-10.98)$ & $7.58(7.51-7.64)$ & 36.59 \\
\hline Indoor & $20.82(20.66-20.98)$ & $22.04(21.89-22.20)$ & $15.7(15.57-15.83)$ & $10.76(10.66-10.9)$ & 35.26 \\
\hline Outdoor & $7.91(7.79-8.03)$ & $8.40(8.27-8.54)$ & $4.33(4.25-4.41)$ & $2.65(2.59-2.71)$ & 42.37 \\
\hline $\begin{array}{l}\text { Average sporozoite rate (\%) } \\
\text { Mean number of infected } \\
\text { anopheles } 95 \% \text { CI }\end{array}$ & $2.24(1.60-3.00)$ & $2.49(1.86-3.25)$ & $1.05(0.57-1.76)$ & $0.75(0.20-1.93)$ & 35.74 \\
\hline Indoor & $2.45(1.7-3.4)$ & $2.52(1.9-3.3)$ & $1.10(0.58-1.9)$ & $0.65(0.13-1.9)$ & 42.55 \\
\hline Outdoor & $0.88(0.17-3.1)$ & $2.11(0.57-5.39)$ & $0.67(0.017-3.8)$ & $1.47(0.04-8.2)$ & 8.49 \\
\hline $\begin{array}{l}\text { Annual entomological inocu- } \\
\text { lation rate }^{\mathrm{a}} \\
\text { Mean number of infectious } \\
\text { bites per person per year } \\
95 \% \text { CI }\end{array}$ & $5.50(3.75-7.86)$ & $6.83(4.89-9.30)$ & $1.41(0.74-2.57)$ & $0.36(0.09-1.02)$ & 79.53 \\
\hline Indoor & $8.87(5.97-12.76)$ & $9.86(6.97-13.63)$ & $2.25(1.13-4.05)$ & $0.45(0.08-1.44)$ & 81.77 \\
\hline Outdoor & $0.62(0.068-2.48)$ & $1.48(0.34-4.09)$ & $0.28(0.01-1.78)$ & $0.26(0.01-1.63)$ & 61.34 \\
\hline
\end{tabular}

Table 5. Crude entomological estimates of mosquito density and malaria transmission in Yaounde during the larviciding control trial. ${ }^{\star}$ Percent reduction $=100-($ Non LCI at baseline/LCI at baseline $\times$ LCI during intervention/non-LCI during intervention) $\times 100$. Non-larviciding intervention area (Non LCI), Larvicidng Intervention area (LCI). ${ }^{a}$ Estimated biting rate ${ }^{\star} 365$ days per year ${ }^{\star}$ mean sporozoite prevalence ${ }^{\star} 1.6$.

\begin{tabular}{|c|c|c|c|c|c|}
\hline \multirow[b]{2}{*}{ Species } & \multicolumn{2}{|l|}{ Baseline } & \multicolumn{2}{|l|}{ Intervention } & \multirow[b]{2}{*}{$\begin{array}{l}\text { Percentage } \\
\text { reduction }\end{array}$} \\
\hline & $\begin{array}{l}\text { Non-intervention } \\
\text { area }(95 \% \mathrm{CI})\end{array}$ & \begin{tabular}{|l|} 
Intervention area \\
$(95 \%$ CI $)$
\end{tabular} & $\begin{array}{l}\text { Non-intervention } \\
\text { area }(95 \% \mathrm{CI})\end{array}$ & $\begin{array}{l}\text { Intervention area } \\
(95 \% \mathrm{CI})\end{array}$ & \\
\hline An. gambiae s.l & $0.39(0.37-0.40)$ & $0.38(0.36-0.40)$ & $0.22(0.21-0.23)$ & $0.061(0.05-0.068)$ & 71.54 \\
\hline An. funestus s.l & $0.029(0.025-0.034)$ & $0.088(0.08-0.096)$ & $0.011(0.009-0.014)$ & $0.020(0.017-0.024)$ & 40.08 \\
\hline
\end{tabular}

Table 6. Impact of larviciding treatments on biting An. gambiae s.l. and An. funestus densities in Yaounde. ${ }^{a}$ Percent reduction $=100-($ Non LCI at baseline/LCI at baseline $\times$ LCI during intervention/non-LCI during intervention) $\times 100$; Non-larviciding intervention area (Non LCI), Larvicidng Intervention area (LCI).

with $68 \%$ reduction of adult anopheline biting density. The density of mosquitoes collected indoor and outdoor in control and intervention area also varied significantly. The highest reduction was recorded with mosquitoes biting indoor $68.27 \%$ versus $57.74 \%$ outdoor (Table 5). When was compared the impact of the intervention on An. gambiae s.l., and An. funestus the two main vectors species in Yaounde, it appeared that An. gambiae s.l., biting density was reduced by over $71 \%$ whereas An. funestus density was reduced by $40 \%$ (Table 6 ).

Crude analysis of sporozoites positive mosquitoes rate estimate showed a significant reduction of the sporozoite rate when binary logistic regression adjusting for years and group was applied $(\mathrm{OR}=0.29 ; 95 \% \mathrm{CI}=0.10-0.80$, $P=0.017)$. The entomological inoculation rate varied in the non-intervention area from 5.50 infected bites/ person/year at the baseline to 1.41 infected bites/person/year during intervention. In the intervention area, the entomological inoculation rate dropped from 6.83 infected bites/person/year at the baseline to 0.36 infected bites/person/year during intervention. This accounted for $79 \%$ (OR $0.21 ; 95 \% \mathrm{CI} 0.14-0.30, P<0.0001$ ) reduction of EIR.

Modeling the effect of larviciding intervention using general estimating equations after adjusting for clusters, years and seasons it appeared that at baseline, vector density and EIR in intervention and non-intervention area were readily comparable while the implementation of larviciding treatment significantly reduced the risk of being bitten by anopheline $(P<0.05)$, all this during the entire intervention period [beginning $(2018)$, midway (2019) and end of the study (2020)] (Table 7).

The influence of house characteristics on mosquito distribution in the intervention and non-intervention areas at baseline and during the intervention is presented in Supplementary Table S2. Parameters of the house (holes on the wall, absence of ceiling, absence of screens on windows) known to increase exposure to mosquito bites were found as contributing to a less important exposure risk in intervention area compared to non-intervention area.

Evolution of An. gambiae s.I. susceptibility to pyrethroids and DDT. Studies conducted indicated a slight increase in the susceptibility status of An. gambiae females to both permethrin (mortality rates $34.16 \%$ 


\begin{tabular}{|l|c|l|}
\hline Parameters & Estimated means $(95 \%$ CI) & P value \\
\hline Baseline & $0.1576(-0.08759,0.4027)$ & 0.1898 \\
\hline Mar 2017-July 2018 & \multicolumn{2}{|l|}{} \\
\hline Intervention & $0.09859(0.05815,0.1388)$ & 0.0203 \\
\hline Sep-Dec 2018 & $0.08299(0.05436,0.1116)$ & 0.0006 \\
\hline 2019 & $0.06197(0.009455,0.1145)$ & 0.0065 \\
\hline 2020 & $0.0009444(1.795 \mathrm{e}-05,0.001871)$ & 0.038 \\
\hline EIR (total)
\end{tabular}

Table 7. Impact of larviciding on biting anopheline densities and malaria transmission intensity estimated using generalized estimating equations (adjusting for years and periods).

\begin{tabular}{|l|l|l|l|l|}
\hline \multirow{2}{*}{} & \multicolumn{4}{|l|}{ Mortality rates/1014F allele frequency } \\
\cline { 2 - 5 } & Pre-intervention & \multicolumn{2}{l|}{ Intervention } \\
\cline { 2 - 5 } & $\mathbf{2 0 1 7}$ & $\mathbf{2 0 1 8}$ & $\mathbf{2 0 1 9}$ & $\mathbf{2 0 2 0}$ \\
\hline Permethrin 0.75\% & $34.16 \%(166 / 486)$ & $7.71 \%(34 / 441)$ & $2.07 \%(10 / 484)$ & $39.26 \%(106 / 270)$ \\
\hline Deltamethrin 0.05\% & $35.19 \%(411 / 1168)$ & $12.30 \%(199 / 1618)$ & $22.40 \%(97 / 433)$ & $44.20 \%(80 / 181)$ \\
\hline DDT 4\% & $1.33 \%(2 / 150)$ & $3.05 \%(35 / 1146)$ & $1.46 \%(5 / 342)$ & $2 \%(4 / 200)$ \\
\hline 1014F Kdr allele frequency & $60 \%$ & $75 \%$ & $67 \%$ & $73 \%$ \\
\hline
\end{tabular}

Table 8. Evolution of An. gambiae sl susceptibility to permethrin, deltamethrin and DDT during preintervention and intervention period in the city of Yaounde.

at beginning to $39.26 \%$ at the end of the intervention) and deltamethrin (mortality rates $35.19 \%$ at beginning to $44.20 \%$ at the end of the intervention) during the trial (Table 8).

The effect of larviciding with VectoMax G on non-target organisms could be found in supplementary Table S3. The study indicated no effect of larviciding treatments on non-target species diversity.

\section{Discussion}

This study's main objective was to assess the impact of larviciding on biting anopheline densities and malaria transmission intensity in the city of Yaounde. The present study used entomological outcomes as primary endpoint rather than epidemiological outcomes because of limited financial means. In Yaounde, over $90 \%$ of households own at least a net and over $70 \%$ of the population report using net regularly ${ }^{43}$. A high reduction of vector density and malaria transmission intensity was recorded with over $68 \%$ reduction of Anopheline densities collected using CDC-LT and 79\% reduction of entomological inoculation rate. These figures are consistent with previous studies conducted across the continent supporting the high impact of antilarval measures on both entomological and epidemiological indicators ${ }^{22,26,27,51}$. The fact that a high number of clusters (including intervention and non-intervention areas) were used and monitored before and during the intervention, mosquito collection was undertaken using the Center for Disease Control Light trap (CDC LT) and the use of different teams involved in the treatment and the monitoring of field sites as recommended by $\mathrm{WHO}^{21,52}$, permitted to minimize the inclusion of bias (performance bias, selection bias, low sample size ...) and further strengthen the quality of evidences deriving from the study. Well-conducted vector control field trials are essential to inform policy making and for evidence-based decision-making ${ }^{52}$. Important reduction of both indoor and outdoor biting anopheline densities was recorded confirming larviciding as a promising tool for controlling outdoor malaria transmission in urban settings.

During the study, continual application of larvicide was conducted rather than seasonal (during the rainy season) as done elsewhere ${ }^{26}$. This regular application of the larvicide led to a high reduction of breeding habitats with anopheline larvae, the density of anopheline larvae and late instar stages. These figures are consistent with previous findings ${ }^{53,54}$. Although studies conducted so far in Yaoundé suggested seasonal malaria transmission pattern $^{40,42,44}$, it is possible that transmission could be occurring at an undetectable rate at some periods of the year due to the permanent presence of An. gambiae sl in the city and gametocyte carriers. This observation supports regular application of larvicide all year long at least during the first years of the intervention. Analysis of the landscape of the city of Yaounde and transmission risk pattern also indicated a heterogeneous malaria risk with some districts more affected than others ${ }^{42,45}$ and is in favor for emphasizing larviciding intervention in high risk zone. An. funestus was less intensely affected by the intervention compared to An. gambiae sl and could derive from the fact that An. funestus breed in water bodies covered by emerging vegetation which could reduce the quantity of larvicide granules getting to water surface and available for larvae whereas, An. gambiae s.l. is mainly found in water bodies without vegetation ${ }^{55}$. Limited impact of larviciding due to vegetation cover was reported in previous studies ${ }^{56}$. 
Several physico-chemical parameters were monitored in the course of the study to assess their influence on mosquito distribution or larviciding treatments efficacy. Some of them including organophosphate, sulphate, conductivity and TDS were found to display different correlation patterns with larval density in intervention compared to non-intervention areas and could translate possible interaction with the larvicide. The possible influence of physico-chemical parameters on microbial larvicide efficacy deserves further assessment.

The composition of the anopheline fauna (particularly An. gambiae and An. coluzzii) did not changed significantly in the intervention and non-intervention areas before and during the intervention, which could suggest similar susceptibility status to larvicide of the two species as earlier suggested for insecticides ${ }^{57}$. Yet, studies conducted so far also indicated different insecticide resistance mechanisms in both An. gambiae and An. coluzzii in the city of Yaounde ${ }^{47}$. Insecticide resistance is largely spread across Yaounde ${ }^{58-60}$ but this seems to have had no impact on the effectiveness of larviciding treatments, since high reduction in anopheline density was recorded. A recent study in the city of Yaoundé indicated longer larval development time for resistant mosquitoes compare to susceptible ${ }^{49}$. This specific characteristic could increase the exposure of resistant mosquitoes to larvicide and increase mortality rate among insecticide resistant larvae. The following further supports the additional benefit of larviciding which could act as a complementary tool for insecticide resistance management ${ }^{61}$. Anti-larval measures could induce a reversal of resistance to pyrethroids and extend the efficacy of pyrethroid LLINs ${ }^{62}$. Microbial larvicides are also known to be highly efficient, specific and safe to use ${ }^{21}$. Moreover, the risk that resistance could emerge is very low due to the complex mode of action of these larvicides particularly Bacillus thuringiensis which has up to four different endotoxins ${ }^{21}$. Following up the susceptibility profile of anopheline mosquitoes suggested no significant evolution of pyrethroid resistance and kdr alleles. However at this stage, it is not clear whether this pattern could be associated to the implementation of larviciding activities or reflect seasonal or temporal variations in Yaounde.

A moderate reduction of adult Culex species biting density was recorded. The limited impact of larviciding treatments on this species could be due to the fact that these mosquitoes breed in different types of habitats such as pit latrines, which were not specifically targeted during larviciding treatments. It may also be possible that the impact of larviciding treatments in drains which are also preferential breeding habitats for Culex could have been limited due to the presence of solid wastes and many hiding places which could have limited the distribution of larvicide in the water ${ }^{45}$. Culex mosquitoes in Yaounde have also been reported to display a high insecticide resistance profile ${ }^{46,63}$.

As for houses, various factors allow mosquitoes to easily get in, including holes in walls, presence of opened eaves or absence of ceiling, which were proven to have a limited influence on indoor biting mosquito's density during intervention, compared to the baseline period in intervention areas. Also, factors preventing mosquitoes from entering houses, such as presence of screens on windows or use of LLINs were found to induce better protection in areas where larviciding intervention was implemented compared to non-intervention areas. Better housing has always been regarded as a factor that could improve protection against mosquito bites in urban settings ${ }^{48,64-66}$.

The impact of the use of the microbial larvicide VectoMax on non-target organisms was also monitored and no significant impact on the non-target microfauna (Cladocerans, Rotifers, Ostracods and Copepods) was recorded. A high diversity of the microfauna was instead recorded in intervention areas. Further studies are needed to assess the effect of this larvicide on the aquatic macrofauna.

This study had some limitations. (1) Due to limited financial resources, the study mainly focused on entomological outcomes as primary endpoints rather than epidemiological outcomes as generally done. However, it provided a proof of concept that larviciding could be a suitable measure for reducing malaria transmission intensity in Yaounde. (2) The study relied on self-report assessment to measure LLIN coverage and use. This could have biased the interpretation of the added effect of larviciding on LLINs. (3) The study did not assess the cost-effectiveness of larviciding which is very important for policymakers.

\section{Conclusion}

This study sets out to advocate the fact that the use of larviciding as a complement to LLINs could be a viable solution for controlling malaria transmission in Yaounde, in a context of rapid expansion of insecticide resistance across Africa and outdoor malaria transmission. The study provided strong evidence supporting the use of larviciding as a main intervention in urban settings. Results obtained should be considered by national control programmes and local Government to implement tailored control approaches to improve the fight against vectorborne diseases in urban settings. Further studies should be carried out to assess the impact of larviciding on epidemiological outcomes in Yaounde, the cost-effectiveness of larviciding with microbial larvicide and ways to involve community in vector control activities to ensure the sustainability of such interventions.

\section{Materials and methods}

Study area. The study was conducted in Yaoundé the capital of Cameroon ( $\left.3^{\circ} 52^{\prime} 12 \mathrm{~N} ; 11^{\circ} 31^{\prime} 12 \mathrm{E}\right)$ (Fig. 3). Yaounde is located $726 \mathrm{~m}$ above sea level and receives up to $1700 \mathrm{~mm}$ of rainfall annually. It displays an equatorial climate with two rainy seasons extending from March to June and from September to November lasting 7 to 8 months. Despite its geographical location in the equatorial forest domain, the extension of settlements has significantly reduced the forest cover mainly found in nearby rural areas. The city extends $20 \mathrm{~km}$ wide and about $25 \mathrm{~km}$ long. Yaounde landscape comprises highlands and lowlands areas crossed by several rivers. Lowland areas are exploited during the dry season for agriculture. Houses are built on both hill slopes and in lowlands. Main rivers crossing the city include rivers Mfoundi, Ekozoa, Biyeme and Mefou. 


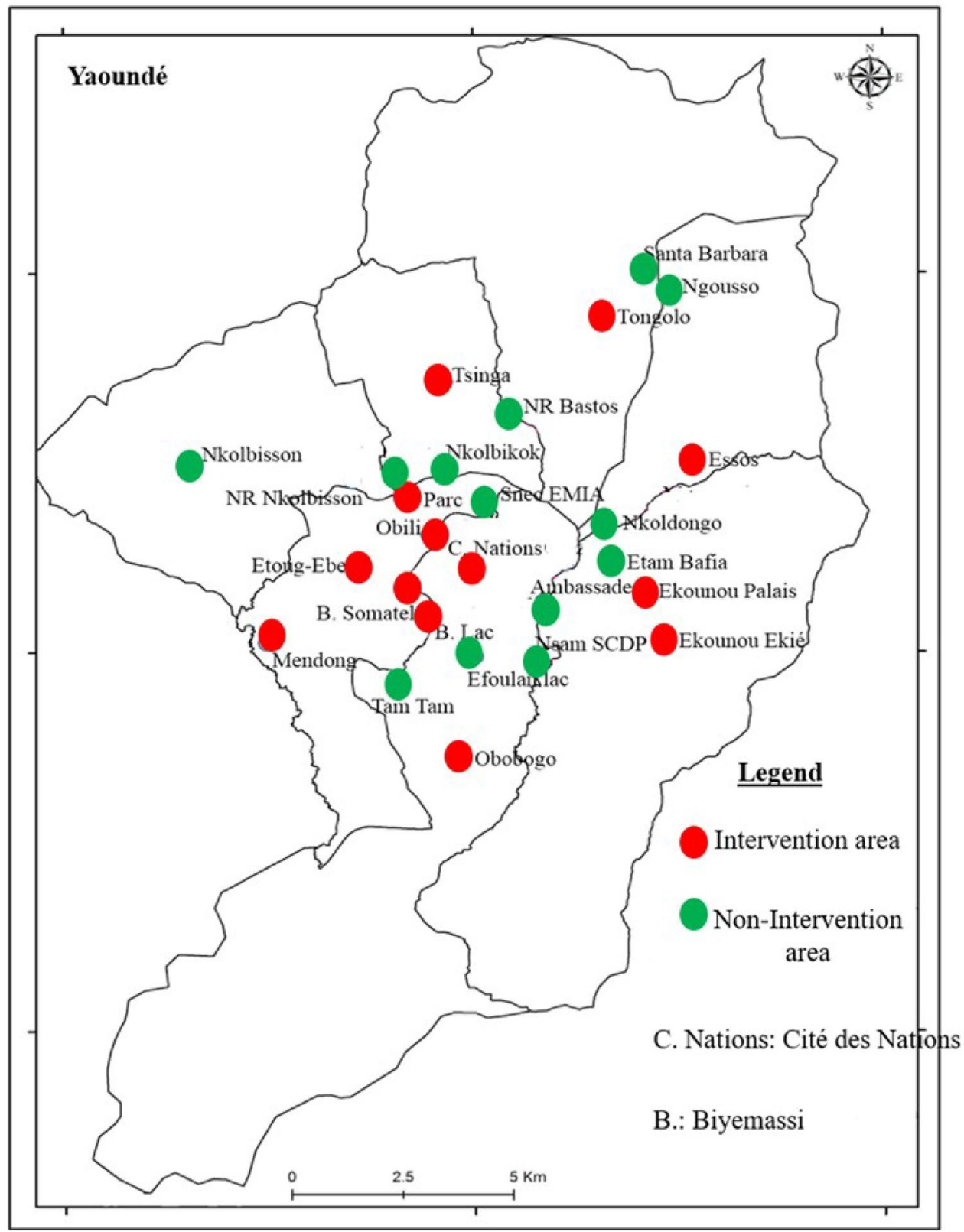

Figure 3. A map of the city of Yaoundé presenting intervention and non-intervention sites. The administrative division of Cameroon is available in open access on the OpenStreetMap platform (https://www.openstreetmap. org/search?query=cameroon\#map=6/ 7.406/12.283). ArcGIS version 10.2.2 sofware (ESRI, Redland, CA, USA; https://www.esri.com/enus/arcgis/about-arcgis/overview) was used to generate the map showing study sites in Yaoundé.

Sample size justification. Assuming a baseline density of 1 anopheline/CDC-trap/night $k=0.3$ with collection conducted in 10 houses/cluster using 13 clusters/arm, it was estimated that the study will have over $80 \%$ power to detect up to $33 \%$ reduction of the density of anopheline collected using CDC-LT at the 5\% significance level.

Study design and larviciding activities. The primary objective of the trial was to assess the effect of larviciding on anopheline mosquito densities and malaria transmission rate in Yaounde. A parallel cluster randomised trial was conducted in twenty-six districts referred to as clusters (Fig. 4). Thirteen clusters served as control whereas the thirteen remaining were the intervention areas. Each cluster was an area of 2 to $4 \mathrm{~km}^{2}$ crossed by a river system encompassing both lowland and highland areas. The lowland part for the majority of clusters was sparsed and exploited for agriculture or with human constructions. The evaluation zone was situated at the center of each cluster always in the lowland area. Clusters were separated from one another by a distance of $500 \mathrm{~m}$ to $1 \mathrm{~km}$ to minimize mosquito spillover from non-intervention to intervention sites. Administra- 


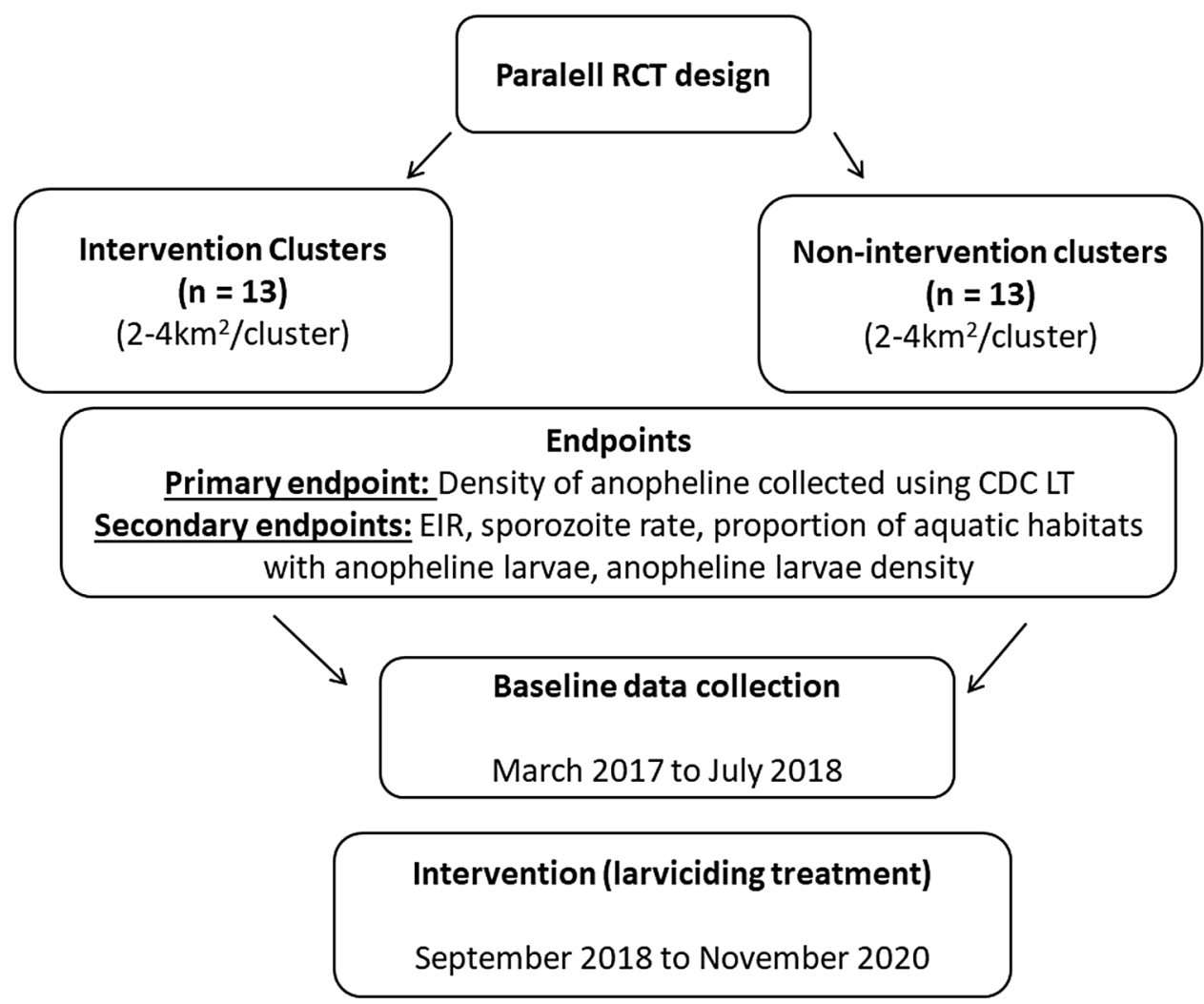

Figure 4. Trial profile design (RCT: Random Control Trial).

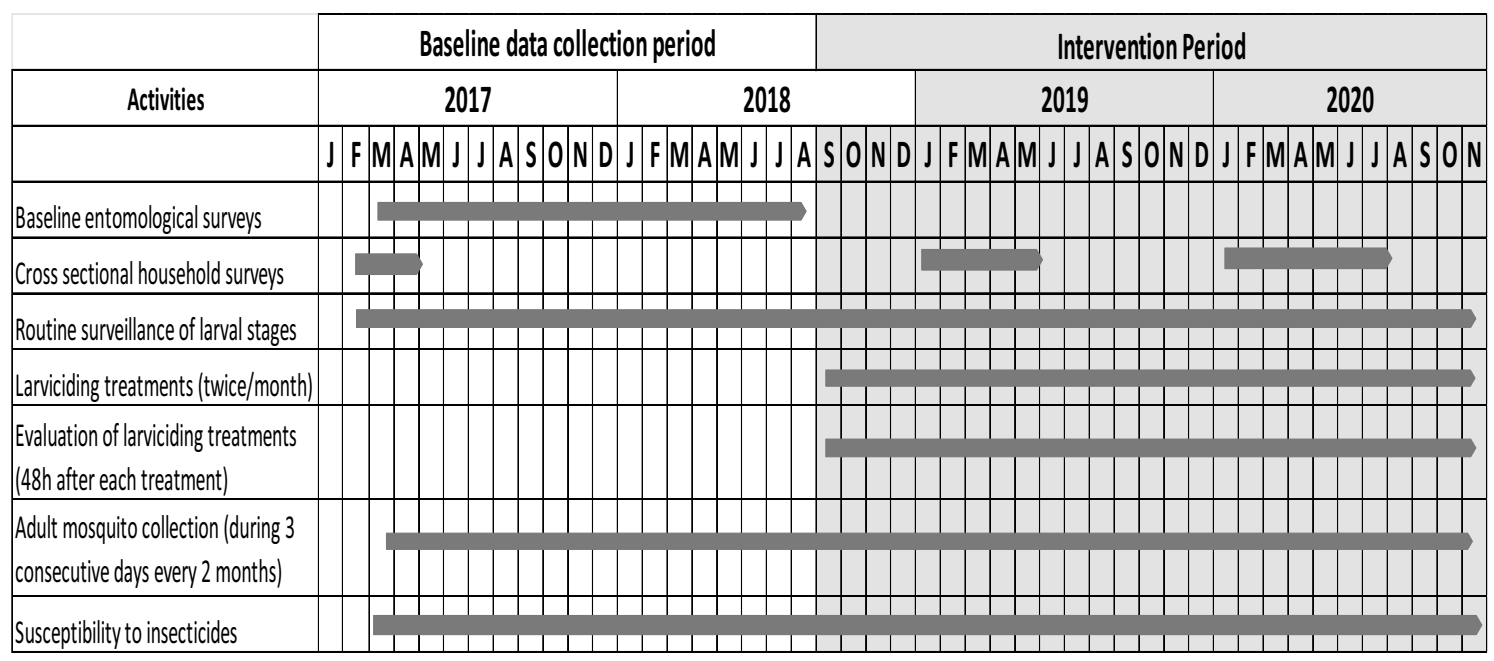

Figure 5. Duration of activities planned during the larviciding trial in the city of Yaounde.

tive boundaries (including roads, railways) were used to determine the limit of clusters. Baseline entomological data were collected from all clusters for 17 months, from March 2017 to July 2018. After this period microbial larvicide was applied in 13 clusters for 27 months (September 2018 to November 2020) (Fig. 4). Adult biting densities collected using CDC light traps were used as the primary outcome. At the baseline, it was noticed that $>90 \%$ of households owned at least one LLIN, but only $58.5 \%$ had one LLIN for two people as requested by the $\mathrm{WHO}^{36}$. At the end of the baseline sampling period, all clusters were ranked according to adult anopheline biting density. Clusters with similar biting density were grouped into pairs and from each pair, one cluster was randomly selected as the intervention site and the other as control using a computer-assisted programme.

Intervention. In intervention clusters, all aquatic habitats which could serve as potential breeding sites for mosquitoes were treated from September 2018 to November 2020 (Fig. 5). It was assumed that when larvicide 
was applied to the entire cluster, the buffer zone and the fact that the evaluation was conducted at the centre of the cluster, could reduce mosquito spillover from non-intervention sites to intervention areas. Treatments were conducted using the larvicide VectoMax (Valent Biosciences Corporation, USA) a granule formulation (CG) containing as active ingredients both B. thuringiensis israelensis (Bti), strain AM65-52 (45 g/kg) and B. sphaericus (Bsph) strain ABTS-1743 (27 g/kg). VectoMax contains 50Bs international toxic units per mg of the product. According to WHO recommendations ${ }^{67}$ this larvicide should be used at the dosage of 500 to $1500 \mathrm{mg} / \mathrm{m}^{2}$ in open water bodies (pools, temporary puddles and artificial containers) with an effect lasting for 2 to 3 weeks. During the trial aquatic habitats were treated once every two weeks by hand application of the larvicide. Field applicators were recruited from local communities. They were supervised during each field trip by one field supervisor in each zone and trained for one month before starting larviciding activities. Application of larvicide was conducted early in the morning between 7 and 11 AM to avoid the hottest time of the day. Teams of three to four male adult applicators conducted the application of larvicide across each cluster. A minimum of 200 aquatic habitats/cluster were treated per day by a team (there were more breeding habitats in the rainy season compare to the dry season). Each team performing larviciding treatments used about 15 to $50 \mathrm{~kg}$ of larvicide/cluster/day depending on the size of the cluster and the availability of aquatic habitats.

Endpoints. To assess the impact of the LSM intervention we used as primary outcome adult anopheline biting density collected using CDC light traps. Secondary outcomes included the entomological inoculation rate, the sporozoite rate, the presence of anopheline larvae in breeding habitats and larval density.

Larval vector abundance. During the study, all aquatic habitats (with or without larvae) were identified and characterised. Their size, physico-chemical characteristics and the presence or absence of anopheline and culicine larvae were recorded every month.

During the intervention, water collection points were checked every week in the intervention area to find out the number of habitats containing early and late instar larvae, to determine the effectiveness of larvicide application. Surveillance of treated aquatic habitats was conducted $48 \mathrm{~h}$ after the treatment by a team of two people (different from those who undertook the treatment) who visited at least $50 \%$ of the treated area and all breeding habitats found with larvae were retreated. Checking larvae in aquatic habitats was also conducted in non-intervention sites once every month to capture the progression of mosquitoes in these sites. All water bodies encountered were geo-located using a Garmin eTrex GPS and recorded in a GIS database for analysis.

Water bodies were analysed to check the presence of mosquito larvae. Aquatic habitats with or without anopheline larvae were all described and registered. The immature stages of mosquitoes were collected using standard dipping technique ${ }^{68}$. Using a $350 \mathrm{ml}$ deeper, three to five dips were performed for small aquatic habitats of less than $1 \mathrm{~m}^{2}$; and five to ten dips for aquatic habitats of more than $1 \mathrm{~m}^{2}$. For some habitats such as tyres or footprints which could be too shallow during certain periods, larval collection was conducted using a pipette. The average larval density $(\mathrm{N})$ was estimated by calculating the ratio of the number of larvae collected per dip (using a dipper with a volume of $350 \mathrm{ml}$ ). Once collected larvae were classified according to their stages: early instars larvae (L1 and L2), late instars (L3, L4) and pupae. Anopheline larvae were separated from the culicines using morphologically identification keys ${ }^{69,70}$. Each anopheline larvae specimen was stored individually at $-20^{\circ} \mathrm{C}$ and molecularly identified.

Physico-chemical characterization of aquatic habitats. Parameters recorded in each breeding site included habitats type, size, depth, exposure to sunlight, presence/absence of vegetation, distance between each water point and the nearest human dwellings, the presence/absence of predators, organic pollution status, proportion of water surface covered by vegetation or algae, aquatic habitats type (stagnant water pools, gutters, well, tire print, footprint, pit latrine....). In addition to these, the following parameters were also recorded: Total Dissolved Solids (TDS), $\mathrm{pH}$, temperature, conductivity using a Jenway multiparametric probe. The concentrations of sulphates, organophosphates, hydrogen peroxide $\left(\mathrm{H}_{2} \mathrm{O}_{2}\right)$, turbidity, iron and calcium were analyzed using a Wagtech spectrophotometer ${ }^{71}$.

Adult mosquitoes sampling. Adult mosquitoes were sampled using the Centre for Disease Control and Prevention Light Traps (CDC-LTs) both indoor and outdoor. Collections were performed once every two months from March 2017 to November 2020. CDC-LTs were placed indoor and outdoor in 10 homes per district. Houses used for adult mosquito collection were selected randomly. Every 50 to $100 \mathrm{~m}$ one house was selected randomly. If consent was not obtained from house owners the house situated next was chosen. The same houses were used for mosquito collection throughout the study. Mosquito collection were undertaken at the center of each cluster. Collections were undertaken from $7 \mathrm{pm}$ to 6 am during 3 consecutive days per district per month in each district.

Mosquito processing. Once collected, anophelines were separated from culicines using morphological identification keys of Edwards et al. ${ }^{72}$. Anopheline species were identified using morphological identification keys of Gillies and De Meillon ${ }^{73}$ and Gillies and Coetzee ${ }^{74}$. Mosquitoes belonging to the Anopheles gambiae complex were further processed by $\mathrm{PCR}^{75}$ to identify between An. coluzzii and An. gambiae the two members of the complex found in Yaoundé. Molecular identification of members of Anopheles funestus group was conducted according to Koekemoer et al. ${ }^{7}$. Both adult and larvae were molecularly identified. DNA extracted from wings and legs or the whole larvae according to Livak method ${ }^{77}$ was used for analysis. Each anopheline specimen was stored individually in a numbered Eppendorf tube containing desiccant, archived and kept in the freezer 
at $-20{ }^{\circ} \mathrm{C}$. Heads and thoraxes of female anophelines were tested to check the presence of circumsporozoite protein (CSP) of Plasmodium falciparum by ELISA, as described by Wirtz et al. ${ }^{78}$ or using TaqMan method $^{79}$.

Insecticide bioassay. Adult females An. gambiae s.l. reared from larval collections in different collection sites were tested using three insecticides (deltamethrin $0.05 \%$, permethrin $0.75 \%$ and DDT $4 \%$ ) following WHO guidelines ${ }^{80}$. An. gambiae s.l. females aged 3-4 days reared from larvae collected on site were placed in batches of 20 to 25 mosquitoes per tube. The mosquitoes were then transferred into tubes with insecticide-impregnated papers and exposed for $1 \mathrm{~h}$. The insecticide susceptible strains An. gambiae s.l. Kisumu and Ngousso strains were used as control to assess the quality of impregnated papers. The number of mosquitoes knocked down by the insecticide was recorded after $1 \mathrm{~h}$ exposure; then, mosquitoes were fed with a $10 \%$ sugar solution and the number of dead mosquitoes recorded $24 \mathrm{~h}$ post-exposure. Mosquitoes subjected to untreated papers were systematically included as controls. To detect the presence of the $k d r$ alleles (L1014F and L1014S) conferring resistance to DDT and pyrethroids, DNA extracted from a sub-sample of An. gambiae s.l. females were screened using the TaqMan assay ${ }^{81}$.

Household surveys. Household surveys were conducted using a questionnaire. The following information was recorded: house characteristics (building material), geographical coordinates of the house, features to prevent mosquitoes from entering (screen, ceiling, close eaves) or those allowing mosquito to enter (holes on the wall, absence of ceiling, open eaves), presence and usage of LLINs, or other antimalarial measures, sociodemographic information of each household (occupation, education level, number of inhabitants per house).

Blinding. Entomological data collection was not blinded to the assignment of mosquito larval control interventions in the different clusters. Field applicators were blinded to the sites selected for larval surveys. Residents were aware of the implementation of the intervention. Adult mosquito collection was conducted using CDC light traps to avoid performance bias. Collections were conducted each month for three consecutive days to lessen variation due to rainfall or temperature. Laboratory technicians processing samples or conducting laboratory analysis were blinded to the identity of the cluster.

Ethical clearance and authorizations. The study was conducted under the ethical clearance $\mathrm{N}^{\circ}$ 2016/11/832/CE/CNERSH/SP delivered by Cameroon National Ethics Committee on Human Health. Further informed consent was obtained from the senior division administrator of the city of Yaoundé and each local District Medical Officer. Verbal and written informed consents were obtained from all respondents and the study purpose was explained to them. Permission to carry the trial was given by the Ministry of Public Health of Cameroon (Reference: 631-06-17). All experiments were performed in accordance with relevant guidelines and regulations.

Research and import permit for the use of VectoMax in Cameroon was granted by the Minister of Trade (Reference IF014167; IF021096; IF031126).

Data analysis. Data were collected on forms, checked first to ensure they were filled comprehensively, then recorded in excel databases. Linear mixed models with random intercepts and Generalized Estimating Equations were used to assess the effect of larviciding treatment on the presence of anopheline larvae (early and late instars) in water collection points as well as adult anopheline density, infection rate and Entomological Inoculation Rate (EIR) respectively. In a preliminary analysis, follow-up curves for the non-intervention and intervention areas were constructed to visualize differences in the responses between the two sites. Average trends and local polynomial regressions of the presence of anopheline larvae (early and late instars) in water collections, anopheline density, infection rate and EIR with date of evaluation were also constructed separately for the different groups to further visualize these differences. We also estimated a null model with random intercept and calculated the intraclass correlation coefficient (ICC) associated with the presence of anopheline larvae, anopheline density, infection rate and EIR respectively. Generalized Estimating Equations were further used to assess the impact of larviciding on anopheline larvae presence in aquatic habitats with clustering by water bodies and zone included as random effects. GEE analyses were also used to assess the impact of larviciding on adult Anopheline density, infection rate and EIR by treating larviciding as a categorical independent factor in the model. Comparisons were adjusted for survey periods (months), years, baseline densities and clustering by traps and cluster. In all these cases, the identity link function with a Gaussian distribution was used, and we resorted to model with independent correlation structures. Clusters were treated as the geographic location, year as the indicator of time, larval presence in aquatic habitats, anopheline densities and EIR estimated as means for each cluster over the full year or the duration of the intervention. Although in the present analysis Clusters were used as the experimental units for the analysis which allowed the impact of larviciding to be estimated, some individual factors operating at the house level were also assessed. We control for individual level factors such as houses by treating individual houses as experimental units and preventing cluster larviciding covariance by restricting our analysis to the 466 houses used for mosquito collection surveyed during both the baseline and intervention period. A first order autoregressive relationship was applied for all repeated measurements. All analyses were carried out with the R 4.0.2 software using the R packages nlme, ggplot2, plyr, lattice, car, effects, emmeans and data.table. Odds ratios and risk ratio were calculated and adjusted for the year of intervention, cluster and season. Binary logistic regression was used to assess the distribution between species and physicochemical parameters in intervention and non-intervention areas. The Entomological inoculation rate was calculated by multiplying the mean density of mosquitoes collected in light traps in each cluster by the proportion of infected mosquitoes, by the number of days in the year and by 1.6 (the coefficient of underestimation of light trap compare to human landing 
catches after preliminary studies). The percentage reduction of mosquito densities and EIR following larviciding intervention were estimated using Mulla formula ${ }^{82}$.

\section{Data availability}

The datasets supporting the findings of this paper are included in this paper.

Received: 27 April 2021; Accepted: 3 August 2021

Published online: 24 August 2021

\section{References}

1. Guengant, J.-P. \& May, J. F. African demography. Glob. J. Emerg. Mark. Econ. 5, 215-267 (2013).

2. Neiderud, C.-J. How urbanization affects the epidemiology of emerging infectious diseases. Infect. Ecol. Epidemiol. 5, 27060 (2015).

3. Eder, M. et al. Scoping review on vector-borne diseases in urban areas: Transmission dynamics, vectorial capacity and co-infection. Infect. Dis. Poverty 7, 1-24 (2018).

4. Keiser, J. et al. Urbanization in sub-Saharan Africa and implication for malaria control. Am. J. Trop. Med. Hyg. 71, 118-127 (2004).

5. Tusting, L. S. et al. Environmental temperature and growth faltering in African children: A cross-sectional study. Lancet Planet. Health 4, e116-e123. https://doi.org/10.1016/S2542-5196(20)30037-1 (2020).

6. Hay, S. I. et al. Climate variability and malaria epidemics in the highlands of East Africa. Trends Parasitol. 21, 52-53 (2005).

7. Bhatt, S. et al. The effect of malaria control on Plasmodium falciparum in Africa between 2000 and 2015. Nature 526, 207-211. https://doi.org/10.1038/nature15535 (2015).

8. Kamau, A., Mogeni, P., Okiro, E. A., Snow, R. W. \& Bejon, P. A systematic review of changing malaria disease burden in sub-Saharan Africa since 2000: Comparing model predictions and empirical observations. BMC Med. 18, 1-11 (2020).

9. Nkumama, I. N., O’Meara, W. P. \& Osier, F. H. Changes in malaria epidemiology in Africa and new challenges for elimination. Trends Parasitol. 33, 128-140 (2017).

10. World Health Organization. World Malaria Report 2020: 20 Years of Global Progress and Challenges (WHO, 2020).

11. World Health Organization. World Malaria Report 2012 (World Health Organization, 2012).

12. Report, W. M. . Licence: CC BY-NC-SA 3.0 IGO (World Health Organization, 2019).

13. Ranson, H. \& Lissenden, N. Insecticide resistance in African Anopheles mosquitoes: A worsening situation that needs urgent action to maintain malaria control. Trends Parasitol. 32, 187-196 (2016).

14. Ranson, H. et al. Pyrethroid resistance in African anopheline mosquitoes: What are the implications for malaria control?. Trends Parasitol. 27, 91-98. https://doi.org/10.1016/j.pt.2010.08.004 (2011).

15. Moyes, C. L. et al. Evaluating insecticide resistance across African districts to aid malaria control decisions. Proc. Natl. Acad. Sci. 117, 22042-22050 (2020).

16. Moyes, C. L. et al. Contemporary status of insecticide resistance in the major Aedes vectors of arboviruses infecting humans. PLoS Negl. Tropi. Dis. 11, e0005625 (2017).

17. Staedke, S. G. et al. LLIN evaluation in Uganda Project (LLINEUP) - Impact of long-lasting insecticidal nets with, and without, piperonyl butoxide on malaria indicators in Uganda: Study protocol for a cluster-randomised trial. Trials 20, 1-13 (2019).

18. Hemingway, J. et al. Country-level operational implementation of the global plan for insecticide resistance management. Proc. Natl. Acad. Sci. 110, 9397-9402. https://doi.org/10.1073/pnas.1307656110 (2013).

19. Chanda, E. et al. Scale-up of integrated malaria vector control: Lessons from Malawi. Bull. World Health Organ. 94, 475 (2016).

20. Derua, Y. A., Kweka, E. J., Kisinza, W. N., Githeko, A. K. \& Mosha, F. W. Bacterial larvicides used for malaria vector control in sub-Saharan Africa: Review of their effectiveness and operational feasibility. Parasit. Vectors 12, 1-18 (2019).

21. WHO. Larval Source Management: A Supplementary Measure for Malaria Vector Control (World Health Organization, 2013).

22. Dambach, P. et al. Reduction of malaria vector mosquitoes in a large-scale intervention trial in rural Burkina Faso using Bti based larval source management. Malar. J. 18, 1-9 (2019).

23. Fillinger, U. \& Lindsay, S. W. Larval source management for malaria control in Africa: Myths and reality. Malar J. https://doi.org/ 10.1186/1475-2875-10-353 (2011).

24. Shousha, A. T. Species-eradication: The eradication of Anopheles gambioe from Upper Egypt, 1942-1945. Bull. World Health Organ. 1, 309 (1948).

25. Utzinger, J., Tozan, Y. \& Singer, B. H. Efficacy and cost-effectiveness of environmental management for malaria control. Trop Med. Int. Health 6, 677-687. https://doi.org/10.1046/j.1365-3156.2001.00769.x (2001).

26. Fillinger, U., Ndenga, B., Githeko, A. \& Lindsay, S. W. Integrated malaria vector control with microbial larvicides and insecticidetreated nets in western Kenya: A controlled trial. Bull. World Health Organ. 87, 655-665 (2009).

27. Choi, L., Majambere, S. \& Wilson, A. L. Larviciding to prevent malaria transmission. Cochrane Database Syst. Rev. 8, CD012736 (2019).

28. Tusting, L. S. et al. Socioeconomic development as an intervention against malaria: A systematic review and meta-analysis. Lancet 382, 963-972. https://doi.org/10.1016/s0140-6736(13)60851-x (2013).

29. Choi, L. \& Wilson, A. Larviciding to control malaria. Cochrane Database Syst. Rev. 2017, CD012736. https://doi.org/10.1002/14651 858.CD012736 (2017).

30. Tusting, L. S. et al. Mosquito larval source management for controlling malaria. Cochrane Database Syst. Rev. 8, CD008923 (2013).

31. Geissbuhler, Y. et al. Microbial larvicide application by a large-scale, community-based program reduces malaria infection prevalence in urban Dar es Salaam. Tanzania. PLoS One. 4, e5107. https://doi.org/10.1371/journal.pone.0005107 (2009).

32. Castro C. M. et al. Community-based environmental management for malaria control: evidence from a small-scale intervention in Dar es Salaam, Tanzania. Malar J. 8, 57 (2009)

33. Maheu-Giroux, M. \& Castro, M. C. Impact of community-based larviciding on the prevalence of malaria infection in Dar es Salaam, Tanzania. PLoS ONE 8, e71638. https://doi.org/10.1371/journal.pone.0071638 (2013).

34. World Health Organization. A Framework for Malaria Elimination (World Health Organization, 2017).

35. Wold Health Organization. 11th World Malaria Day "Ready to Beat Malaria" We are the Generation that can End Malaria (ed. World Health Organization). (World Health Oraganization, 2018).

36. Institut National de Statistiques and IFC. Enquête Démographique et de Santé du Cameroun (ed. INS. ICF.) 1-515 (INS, 2020).

37. Barbazan, P. et al. Control of Culex quinquefasciatus (Diptera: Culicidae) with Bacillus sphaericus in Maroua, Cameroon. J. Am. Mosq. Control Assoc. 13, 263-269 (1997).

38. Hougard, J.-M. et al. Lutte contre Culex quinquefasciatus par Bacillus sphaericus: résultats d'une campagne pilote dans une agglomération urbaine d'Afrique équatoriale. Bulletin de lorganisation mondiale de la santé 71, 367-375 (1994).

39. Antonio-Nkondjio, C. et al. Anopheles gambiae distribution and insecticide resistance in the cities of Douala and Yaoundé (Cameroon): Influence of urban agriculture and pollution. Malar J. https://doi.org/10.1186/1475-2875-10-154 (2011).

40. Tene Fossog, B. et al. Water quality and Anopheles gambiae larval tolerance to pyrethroids in the cities of Douala and Yaounde (Cameroon). J. Trop. Med. 2012, 1-10. https://doi.org/10.1155/2012/429817 (2012). 
41. Fondjo, E., Robert, V., Le Goff, G., Toto, J. \& Carnevale, P. Urban malaria transmission in Yaounde (Cameroon). 2. Entomologic study in 2 semi urban districts. Bull. Soc. Pathol. Exot. 85, 57-63 (1992).

42. Manga, L., Robert, V., Messi, J., Desfontaines, M. \& Le Carnevale, P. paludisme urbain à Yaoundé, Cameroun. 1-Etude entomologique dans deux quartiers centraux. Mém. Soc. R Belge Entomol. 35, 155-162 (1992).

43. Doumbe-Belisse, P. et al. High malaria transmission sustained by Anopheles gambiae sl occurring both indoors and outdoors in the city of Yaoundé, Cameroon. Wellcome Open Res. 3, 164 (2018).

44. Talipouo, A. et al. Malaria prevention in the city of Yaoundé: Knowledge and practices of urban dwellers. Malar. J. 18, 167. https:// doi.org/10.1186/s12936-019-2799-6 (2019).

45. Djamouko-Djonkam, L. et al. Implication of Anopheles funestus in malaria transmission in the city of Yaoundé, Cameroon. Parasite 27, 10 (2020).

46. Djamouko-Djonkam, L. et al. Spatial distribution of Anopheles gambiae sensu lato larvae in the urban environment of Yaoundé, Cameroon. Infect. Dis. Poverty 8, 1-15 (2019).

47. Nchoutpouen, E. et al. Culex species diversity, susceptibility to insecticides and role as potential vector of Lymphatic filariasis in the city of Yaoundé, Cameroon. PLoS Negl. Trop. Dis. 13, e0007229 (2019).

48. Bamou, R. et al. Status of insecticide resistance and its mechanisms in Anopheles gambiae and Anopheles coluzzii populations from forest settings in south Cameroon. Genes 10, 741 (2019).

49. Ngadjeu, C. S. et al. Influence of house characteristics on mosquito distribution and malaria transmission in the city of Yaoundé, Cameroon. Malar. J. 19, 53 (2020).

50. Nkahe, D. L. et al. Fitness cost of insecticide resistance on the life-traits of a Anopheles coluzzii population from the city of Yaoundé, Cameroon. Wellcome Open Res. 5, 171 (2020).

51. Historique-Meteo. https://www.historique-meteo.net/afrique/cameroun/ (2020).

52. Govella, N. et al. A new tent trap for sampling exophagic and endophagic members of the Anopheles gambiae complex. Malar. J. 8, 157. https://doi.org/10.1186/1475-2875-8-157 (2009).

53. Wilson, A. L. et al. Evidence-based vector control? Improving the quality of vector control trials. Trends Parasitol. 31, 380-390 (2015).

54. Fillinger, U., Sonye, G., Killeen, G. F., Knols, B. G. \& Becker, N. The practical importance of permanent and semipermanent habitats for controlling aquatic stages of Anopheles gambiae sensu lato mosquitoes: Operational observations from a rural town in western Kenya. Trop. Med. Int. Health 9, 1274-1289 (2004).

55. Majambere, S., Lindsay, S. W., Green, C., Kandeh, B. \& Fillinger, U. Microbial larvicides for malaria control in The Gambia. Malar. J. 6, 1-14 (2007).

56. Gillies, M. T. \& Coetzee, M. A Supplement to the Anophelinae of Africa South of the Sahara (Afrotropical Region) (South African Institute for Medical Research, 1987).

57. Majambere, S. et al. Is mosquito larval source management appropriate for reducing malaria in areas of extensive flooding in The Gambia? A cross-over intervention trial. Am. J. Trop. Med. Hyg. 82, 176-184 (2010).

58. Fossog Tene, B. et al. Resistance to DDT in an urban setting: Common mechanisms implicated in both M and S forms of Anopheles gambiae in the City of Yaoundé, Cameroon. PLoS ONE 8, e61408. https://doi.org/10.1371/journal.pone.0061408 (2013).

59. Antonio-Nkondjio, C. et al. Investigation of mechanisms of bendiocarb resistance in Anopheles gambiae populations from the city of Yaoundé, Cameroon. Malar. J. 15, 424. https://doi.org/10.1186/s12936-016-1483-3 (2016).

60. Antonio-Nkondjio, C. et al. Rapid evolution of pyrethroid resistance prevalence in Anopheles gambiae populations from the cities of Douala and Yaoundé (Cameroon). Malar. J. 14, 155. https://doi.org/10.1186/s12936-015-0675-6 (2015).

61. Bamou, R. et al. Assessment of the Anophelinae blood seeking bionomic and pyrethroids resistance of local malaria vectors in the forest region of Southern Cameroon. JEZS 8, 1054-1062 (2020).

62. World Health Organization. The Role of Larviciding for Malaria Control in Sub-Saharan Africa: Interim Position Statement (World Health Organization, 2012).

63. Talipouo, A. et al. High insecticide resistance mediated by different mechanisms in Culex quinquefasciatus populations from the city of Yaoundé, Cameroon. Sci. Rep. 11, 1-11 (2021).

64. Haines, A. et al. Promoting health and advancing development through improved housing in low-income settings. J. Urban Health 90, 810-831 (2013).

65. Tusting, L. S. et al. Housing improvements and malaria risk in sub-Saharan Africa: A multi-country analysis of survey data. PLoS Med. 14, e1002234. https://doi.org/10.1371/journal.pmed.1002234 (2017).

66. Tusting, L. S. et al. The evidence for improving housing to reduce malaria: A systematic review and meta-analysis. Malar. J. 14, 209. https://doi.org/10.1186/s12936-015-0724-1 (2015).

67. Organization, W. H. Report of the Nineteenth WHOPES Working Group Meeting: WHO/HQ, Geneva, 8-11 February 2016: Review of Veeralin LN, VectoMax GR, Bactivec SC.(World Health Organization, 2016).

68. Service M. Mosquito Ecology. Field Sampling Methods (Elsevier Applied Science, 1993).

69. Edwards, F. W. Mosquitoes of the Ethiopian Region. HI.-Culicine Adults and Pupae. Mosquitoes of the Ethiopian Region. HI.Culicine Adults and Pupae (1941).

70. Edwards, F. W. Mosquitoes of the Ethiopian region. III, Culicine adults and pupae (Brit. Mus. Nat. Hist., 1941).

71. Gillies, M. \& Coetzee, M. A supplement to the Anophelinae of Africa south of the Sahara (Afrotropical region). Pub South Afr Inst Med Res 55, 143 (1987).

72. Wagtech, P. Water Quality Testing 1-139. https://www.palintest.com/product-categories/wagtech/ (Wagtech, 2012).

73. Gillies, M. T. \& DeMeillon, B. The Anopheline of Africa, south of the Sahara (Ethiopian zoogeographical region) Johannesburg: publication of south African Institute of Medical Research no. 54. (SAIMR, 1968).

74. Gillies, T. \& Coetzee, M. Supplement of the Anopheles of Africa south of Sahara (Afrotropical region) (Publication of the South African Institute of Medical Research, 1987).

75. Santolamazza, F. et al. Distribution of knock-down resistance mutations in Anopheles gambiae molecular forms in west and westcentral Africa. Malar. J. 7, 74 (2008).

76. Koekemoer, L., Kamau, L., Hunt, R. \& Coetzee, M. A cocktail polymerase chain reaction assay to identify members of the Anopheles funestus (Diptera: culicidae) group. Am. J. Trop. Med. Hyg. 66, 804-811 (2002).

77. Livak, K. J. Organization and mapping of a sequence on the Drosophila melanogaster $\mathrm{X}$ and $\mathrm{Y}$ chromosomes that is transcribed during spermatogenesis. Genetics 107, 611-634 (1984).

78. Wirtz, R., Burkot, T., Graves, P. \& Andre, R. Field evaluation of enzymelinked immunosorbent assays for P. falciparum and P. vivax sporozoites in mosquitoes (Diptera: Culicidae) from Papua, new Guinea. J. Med. Entomol. 24, 433-437. https://doi.org/10.1093/ jmedent/24.4.433 (1987).

79. Bass, C. et al. PCR-based detection of Plasmodium in Anopheles mosquitoes: A comparison of a new high-throughput assay with existing methods. Malar. J. 7, 177 (2008).

80. WHO. Test Procedures for Insecticide Resistance Monitoring in Malaria Vector Mosquitoes (WHO, 2013). https://doi.org/10.1371/ journal.pone.0013140.

81. Bass, C. et al. Detection of knockdown resistance (kdr) mutations in Anopheles gambiae: A comparison of two new high-throughput assays with existing methods. Malar. J. 6, 1-14. https://doi.org/10.1186/1475-2875-6-111 (2007). 
82. Mulla, M. S., Norland, L. R., Fanara, D. M., Darwazeh, H. A. \& McKean, D. W. Control of chironomid midges in recreational lakes. J. Econ. Entomol. 64, 300-307 (1971).

\section{Acknowledgements}

This work received financial support from Wellcome Trust senior Fellowship in Public Health and Tropical Medicine (202687/Z/16/Z) to CAN. The funding body did not had any role in the design, data collection, analysis and interpretation of data and in writing the manuscript. We thank Mr. Fessuh Bertrand for his assistance on statistical analysis. We thank the authorities and the population of selected study sites in Yaounde.

\section{Author contributions}

Conceived and designed the study protocol: C.W., C.A.N., Conducted field and laboratory analysis: D.B.P., N.C.S., T.A., K.E., B.R., D.D.L., N.L., S.C.N., T.R., M.P.A., P.A.A. critically revised the manuscript: A.F.D., T.R., B.D.J., P.A.A., C.W.; Interpreted, analysed data and wrote the paper: C.A.N. with contribution of other authors. All the authors read and approved the final version.

\section{Competing interests}

The authors declare no competing interests.

\section{Additional information}

Supplementary Information The online version contains supplementary material available at https://doi.org/ 10.1038/s41598-021-96362-z.

Correspondence and requests for materials should be addressed to C.A.-N.

Reprints and permissions information is available at www.nature.com/reprints.

Publisher's note Springer Nature remains neutral with regard to jurisdictional claims in published maps and institutional affiliations.

(c) (i) Open Access This article is licensed under a Creative Commons Attribution 4.0 International License, which permits use, sharing, adaptation, distribution and reproduction in any medium or format, as long as you give appropriate credit to the original author(s) and the source, provide a link to the Creative Commons licence, and indicate if changes were made. The images or other third party material in this article are included in the article's Creative Commons licence, unless indicated otherwise in a credit line to the material. If material is not included in the article's Creative Commons licence and your intended use is not permitted by statutory regulation or exceeds the permitted use, you will need to obtain permission directly from the copyright holder. To view a copy of this licence, visit http://creativecommons.org/licenses/by/4.0/.

(c) The Author(s) 2021 